\title{
Persistência do Acetochlor em Solo sob Semeadura Direta e CONVENCIONAL ${ }^{1}$
}

\author{
Acetochlor Persistence in Soil Under No-Tillage and Conventional Systems
}

FERRI, M.V.W. ${ }^{2}$ e VIDAL, R.A. ${ }^{3}$

\begin{abstract}
RESUMO - O manejo do solo pode alterar a persistência dos herbicidas e influi na atividade para controle de plantas daninhas, no potencial de injúria das culturas em sucessão e no risco de contaminação ambiental. Um experimento foi conduzido, no ano agrícola de 1999/2000, na Faculdade de Agronomia da Universidade Federal do Rio Grande do Sul, com o objetivo de avaliar a persistência do herbicida acetochlor em Argissolo Vermelho manejado sob semeadura direta e preparo convencional. A dose de acetochlor utilizada foi de $3.360 \mathrm{~g} \mathrm{ha}^{-1}$. O delineamento experimental foi o de blocos casualizados, com três repetições. A persistência do herbicida acetochlor foi avaliada através de bioensaio, utilizando-se o trigo (Triticum aestivum) como planta indicadora. O herbicida acetochlor foi menos persistente no solo sob semeadura direta que sob preparo convencional, com meia-vida de 10 e 29 dias, respectivamente.
\end{abstract}

Palavras-chave: Triticum aestivum, manejo de solos, atividade biológica, persistência, meia-vida.

\begin{abstract}
Soil management affects herbicide persistence, weed control, crop injury and environmental risks. An experiment was carried out at the Universidade Federal do Rio Grande do Sul - Rio Grande do Sul state, Brazil to evaluate the persistence of acetochlor herbicide in conventional tillage and no-tilage systems. The soil was classified as Paleudult. The tested dose of the herbicide was $3.360 \mathrm{~g} \mathrm{ha}^{-1}$. The persistence of acetochlor was evaluated in a bio-assay using wheat (Triticum aestivum). Assessments included plant height and dry matter. Acetochlor half-life was 10 and 29 days under no-tillage and conventional tilled system, respectively.
\end{abstract}

Key words: Triticum aestivum, soil management, bioactivity, persistence, half-life.

\section{INTRODUÇÃO}

A persistência do herbicida no solo pode ser desejável ou não, dependendo dos efeitos sobre o manejo das plantas daninhas, das culturas em sucessão e do risco de contaminação ambiental. Ela é desejável quando a atividade residual resulta em maior período e eficácia de controle das plantas daninhas (Gazziero et al., 1997). É indesejável quando resulta em injúria para as culturas em sucessão ou aumento dos riscos de contaminação ambiental.
As plantas daninhas afetam a expressão do potencial produtivo pelas culturas através da densidade de plantas e da época e duração da competição proporcionada pelas plantas daninhas. O período crítico de interferência é definido como aquele em que as culturas devem permanecer livres da presença das plantas daninhas, a fim de melhor expressar seu potencial produtivo (Durigan et al., 1983; Fleck et al., 1989). Dessa forma, é desejável que a atividade residual dos herbicidas abranja este período e evite, assim, perdas de rendimento devido à

Recebido para publicação em 15/1/2002 e na forma revisada em 15/3/2002.

2 Eng.-Agr. Dr., Caixa Postal 138, 85550-000 Coronel Vivida-PR, <mvwferri@ bol.com.br>. ${ }^{3}$ Eng.-Agr. Ph.D., Professor do Dep. de Plantas de Lavoura da Faculdade de Agronomia da Universidade Federal do Rio Grande do Sul - UFRGS, Av. Bento Gonçalves 7712, 91501-970 Porto Alegre-RS. 
competição com as plantas daninhas.

Além dos efeitos sobre o controle das plantas daninhas, a persistência eleva o risco ambiental, por potencializar a contaminação de águas superficiais e subterrâneas, através do transporte das moléculas dos herbicidas por lixiviação ou com a água e/ou sedimentos que escorrem superficialmente durante o processo erosivo dos solos agrícolas (Workman et al., 1995; Stearman \& Wells, 1997). A lixiviação, a adsorção e a degradação e/ou transformação biológica são os principais processos de redução da persistência dos herbicidas nos solos agrícolas, sendo eles influenciados pelo manejo de solo e pelas variáveis climáticas. O manejo altera esses processos, em razão dos efeitos sobre estrutura, conteúdo de matéria orgânica, $\mathrm{pH}$, temperatura e umidade do solo (Walker et al., 1992; William et al., 1997).

A semeadura direta, devido à não-mobilização do solo e manutenção do solo coberto com palha, eleva o conteúdo superficial de matéria orgânica e reduz as amplitudes de variação da temperatura e umidade do solo. Em razão disso, incrementam-se a biomassa e atividade microbiana e a biotransformação das moléculas dos herbicidas no solo (Weed et al., 1995; Reddy et al., 1995). Além dos efeitos sobre a atividade biológica, o incremento da matéria orgânica favorece a adsorção dos herbicidas no solo (Shaw \& Murphy, 1997). A manutenção da estabilidade da estrutura, com possibilidade de ocorrência de fluxo preferencial, em razão da presença de macroporos nos solos sob semeadura direta, pode também ser considerada um mecanismo de aumento da lixiviação e redução da persistência dos herbicidas na superfície do solo (Isensee et al., 1990).

Assim, a adsorção, a lixiviação, o escorrimento superficial para fora da área tratada e a degradação biológica e química, de forma interagida, regulam a concentração e a persistência das moléculas dos herbicidas na solução do solo e a biodisponibilidade para o controle das plantas daninhas, a fitotoxicidade das culturas e o risco de contaminação ambiental. O objetivo deste estudo foi avaliar a persistência do herbicida acetochlor em solos submetidos aos sistemas de semeadura direta e convencional.

Planta Daninha, Viçosa-MG, v.20, n.1, p.133-139, 2002

\section{MATERIAL E MÉTODOS}

O experimento foi conduzido a campo, no ano agrícola de 1999/2000, na Estação Experimental Agronômica da Universidade Federal do Rio Grande do Sul (EEA/UFRGS), em Eldorado do Sul, região fisiográfica da Depressão Central do RS, em solo classificado pelo Sistema Brasileiro de Classificação de Solos (Embrapa, 1999) como Argissolo Vermelho Distrófico típico, manejado sob o sistema de semeadura direta (seis anos consecutivos) e preparo convencional. Em laboratório, no Departamento de Plantas de Lavoura da Faculdade de Agronomia da UFRGS, foi realizado bioensaio, cuja cultura indicadora foi o trigo, cultivar EMBRAPA 64.

O delineamento experimental utilizado foi o de blocos casualizados, com três repetições, sendo os tratamentos distribuídos em parcelas subdivididas. Nas parcelas principais encontrase o preparo de solo - semeadura direta e preparo convencional - e nas subparcelas, as épocas de avaliação: 1, 7, 14, 35 e 70 dias após aplicação do herbicida (DAT).

O herbicida avaliado foi o acetochlor, 2-cloro-n-(etoximetil)-n-(2-etil-6-metil-fenil) acetamida, na dose de $3.360 \mathrm{~g} \mathrm{ha}^{-1}$. Sua aplicação foi feita com pulverizador costal pressurizado à pressão de $200 \mathrm{kPa}$, com bicos tipo leque 8002 , distanciados em $0,50 \mathrm{~m}$ na barra de $1,5 \mathrm{~m}$, e volume de calda de $220 \mathrm{~L} \mathrm{ha}^{-1}$.

A cobertura do solo com palha, no solo sob semeadura direta, foi obtida através da semeadura de aveia (Avena strigosa), em junho de 1999. Nessa área, a cultura da aveia e as plantas daninhas presentes na superfície do solo foram controladas com o herbicida glifosato a $1.080 \mathrm{~g} \mathrm{ha}^{-1}$, dois dias antes da aplicação do herbicida acetochlor. No momento da aplicação deste herbicida, a cobertura do solo com palha, no solo sob semeadura direta, era de $4 \mathrm{t} \mathrm{ha}^{-1}$. Durante a condução do experimento foram realizadas irrigações de $18 \mathrm{~mm}$ de água às 3 horas e aos 14, 21, 28, 35 e 70 DAT. Aos 6 DAT ocorreu precipitação pluvial de $20 \mathrm{~mm}$.

A persistência do herbicida acetochlor no solo foi determinada através de bioensaio, utilizando o trigo (Triticum aestivum), cultivar EMBRAPA 64, como planta indicadora. A profundidade de solo estudada foi de $10 \mathrm{~cm}$. A 
coleta do solo para bioensaio foi realizada com tubos de PVC de $50 \mathrm{~mm}$ de diâmetro e $20 \mathrm{~cm}$ de altura. Em todas as épocas e em ambos os sistemas de preparo, foram coletados solos sem o herbicida acetochlor, utilizados como testemunha, para verificar a persistência deste herbicida no solo. Após cada coleta, as amostras foram armazenadas a $5 \stackrel{\circ}{\circ}$, para posterior avaliação da persistência. Para isso, as colunas foram cortadas longitudinalmente na região terço-superior, permitindo a semeadura de sementes de trigo pré-germinadas. O desenvolvimento das plantas ocorreu em laboratório, em câmara de crescimento à temperatura de $22{ }^{\circ} \mathrm{C}$ e fotoperíodo de 12 horas. A resposta das plantas à presença do herbicida acetochlor foi avaliada aos 11 dias da emergência, por meio da avaliação da produção da matéria seca da parte aérea e altura de plantas.

A presença do herbicida acetochlor para cálculo de sua meia-vida nos solos de semeadura direta e preparo convencional foi determinada comparando-se o crescimento das plantas de trigo no solo coletado em campo, tratadas com o herbicida, com curvas de resposta obtidas pelo crescimento do trigo em solo contendo acetochlor nas doses correspondentes a 0,$0 ; 52,0 ; 105,0 ; 210,0 ; 420,0 ; 840,0$; $1.680,0$ e $3.360,0 \mathrm{~g} \mathrm{ha}^{-1}$ de ingrediente ativo. Após a aplicação o solo foi agitado, com o objetivo de homogeneizar a distribuição do herbicida neste. Em seguida, foram semeadas sementes de trigo pré-germinadas, a fim de uniformizar a emergência das plantas, em $250 \mathrm{~g}$ de solo tratado ou não com o herbicida acetochlor e acondicionado no interior de potes plásticos. $\mathrm{O}$ desenvolvimento das plantas ocorreu em câmara de crescimento nas mesmas condições ambientais do bioensaio.

A persistência do acetochlor foi calculada através da cinética de dissipação de herbicidas no solo (Paul \& Clark, 1989), utilizando-se a equação 1:

$$
\operatorname{Ln}([\mathrm{Cf}] /[\mathrm{Ci}]=-\mathrm{k} \mathrm{t}
$$

em que [Ci] e [Cf] são as concentrações do herbicida acetochlor indicadas pelo bioensaio no tempo inicial e final, respectivamente, $\mathrm{k}$ é a constante de dissipação e t é o tempo. A meiavida $\left(\mathrm{t}_{1 / 2}\right)$ no solo foi calculada pela equação 2 :

$$
\mathrm{t}_{1 / 2}=0,693 / \mathrm{k}
$$

Além disso, foi realizada caracterização física do solo através da avaliação da densidade, macroporosidade, microporosidade e porosidade total do solo, bem como da condutividade hidráulica saturada, por meio de metodologias descritas no Manual de Métodos de Análise de Solo (Embrapa, 1979). Foi determinado também o carbono orgânico total do solo, conforme metodologia descrita por Tedesco et al. (1995).

Na análise estatística, foram considerados os valores correspondentes a porcentagem de redução de altura e matéria seca das plantas de trigo em relação à testemunha sem herbicida. O dados sofreram transformação arco seno $\sqrt{\mathrm{x} / 100}$ ao serem submetidos à análise de variância. A variação da presença do herbicida acetochlor no tempo, em função do preparo e da cobertura do solo com palha, foi avaliada pelo intervalo de confiança da média em nível de 5\% de probabilidade pelo teste $t$. Foi avaliado, também, o grau de correlação entre a meia-vida $\left(t_{1 / 2}\right)$ do herbicida acetochlor e o preparo e cobertura do solo com palha, verificando-se o nível de significância do coeficiente de correlação (r).

\section{RESULTADOS E DISCUSSÃO}

Os dados da Tabela 1 mostram diferenças entre o Argissolo Vermelho sob semeadura direta e aquele sob preparo convencional para todas as variáveis estudadas. Observou-se maior densidade e microporosidade na profundidade de $0-5 \mathrm{~cm}$ para o solo sob semeadura direta. Observou-se, também, que este sistema de manejo apresentou menor densidade do solo que o preparo convencional na profundidade de $15-20 \mathrm{~cm}$. A porosidade total e a macroporosidade foram maiores no solo com preparo convencional na profundidade de $0-5 \mathrm{~cm}$ e no solo sob semeadura direta na profundidade de $15-20 \mathrm{~cm}$. Além disso, o carbono orgânico total, na profundidade de $0-10 \mathrm{~cm}$, foi maior na semeadura direta. Na profundidade de $0-10 \mathrm{~cm}$, a condutividade hidráulica saturada foi maior no solo sob preparo convencional, e na profundidade de $10-20 \mathrm{~cm}$ ela foi maior na semeadura direta (Tabela 1). O preparo do solo, por ter elevado a porosidade total e a macroposidade na profundidade de $0-5 \mathrm{~cm}$, pode ter favorecido a condutividade hidráulica saturada na profundidade de $0-10 \mathrm{~cm}$, enquanto a ausência de 
preparo do solo e a conseqüente manutenção da estabilidade da estrutura podem ter favorecido a condutividade hidráulica saturada na profundidade de $10-20 \mathrm{~cm}$ no solo sob semeadura direta.

A presença de palha na superfície do solo pode ter contribuído para elevar o teor superficial de carbono orgânico na semeadura direta, como também observado por Dick (1983) e Rhoton et al. (1993). Estudos envolvendo o efeito do preparo do solo sobre as características físicas e químicas, em profundidade no solo, normalmente produzem resultados variáveis, dependendo da textura, do sistema e tempo de preparo e da profundidade do solo avaliada. A ausência de preparo normalmente pode promover o aumento da densidade e o do teor de carbono orgânico nas camadas superficiais do solo; já o preparo do solo promove o aumento da macroporosidade e a redução da densidade do solo (Blewins et al., 1983; Dick, 1983; Shipitalo et al., 2000).

A análise estatística evidenciou interação entre preparo de solo e época de avaliação para as variáveis altura de plantas (Figura 1) e matéria seca da parte aérea (Figura 2). Esse resultado indica que o herbicida acetochlor permaneceu ativo em período superior no solo Argissolo Vermelho sob preparo convencional, comparado à semeadura direta, indicando que este último sistema de manejo do solo reduz a persistência do herbicida acetochlor.

Tabela 1 - Densidade, macro, micro e porosidade total, condutividade hidráulica saturada e carbono orgânico total, em diferentes profundidades de coleta, em Argissolo Vermelho sob semeadura direta e preparo convencional. EEA/UFRGS, Eldorado do Sul-RS, 1999/2000

\begin{tabular}{|c|c|c|c|c|c|c|c|c|c|c|c|c|}
\hline \multirow{3}{*}{$\begin{array}{l}\text { Profundidade } \\
\text { do solo }(\mathrm{cm})\end{array}$} & \multicolumn{2}{|c|}{$\begin{array}{l}\text { Densidade do } \\
\text { solo }\left(\mathrm{g} \mathrm{cm}^{-3}\right)\end{array}$} & \multicolumn{2}{|c|}{$\begin{array}{l}\text { Macroporosidade } \\
\qquad\left(\mathrm{m}^{3} \mathrm{~m}^{-3}\right)\end{array}$} & \multicolumn{2}{|c|}{$\begin{array}{l}\text { Microporosidade } \\
\qquad\left(\mathrm{m}^{3} \mathrm{~m}^{-3}\right)\end{array}$} & \multicolumn{2}{|c|}{$\begin{array}{c}\text { Porosidade } \\
\text { total }\left(\mathrm{m}^{3} \mathrm{~m}^{-3}\right)\end{array}$} & \multicolumn{2}{|c|}{$\begin{array}{c}\text { Condutividade } \\
\text { hidráulica saturada } \\
\qquad\left(\mathrm{cm} \mathrm{h}^{-1}\right)^{\underline{1} /}\end{array}$} & \multicolumn{2}{|c|}{$\begin{array}{l}\text { Carbono orgânico } \\
\text { total }\left(\mathrm{mg} \mathrm{g}^{-1}\right)\end{array}$} \\
\hline & \multicolumn{12}{|c|}{ Sistemas de preparo de solo } \\
\hline & SD & $\mathrm{PC}$ & SD & $\mathrm{PC}$ & SD & $\mathrm{PC}$ & SD & $\mathrm{PC}$ & SD & $\mathrm{PC}$ & SD & $\mathrm{PC}$ \\
\hline $0-5$ & $1,64 \mathrm{Ca}$ & $1,34 \mathrm{Db}$ & $0,193 \mathrm{Ab}$ & 0,279 Aa & $0,170 \mathrm{BCa}$ & $0,138 \mathrm{Db}$ & $0,363 \mathrm{ABb}$ & $0,415 \mathrm{Aa}$ & & & $15,1 \mathrm{Aa}$ & $12,8 \mathrm{Ab}$ \\
\hline $5-10$ & $1,66 \mathrm{BCa}$ & $1,59 \mathrm{Ca}$ & $0,217 \mathrm{Aa}$ & $0,204 \mathrm{Ba}$ & $0,164 \mathrm{Ca}$ & $0,159 \mathrm{Ca}$ & $0,381 \mathrm{Aa}$ & $0,363 \mathrm{Ba}$ & $15,8 \mathrm{Ab}$ & $24,1 \mathrm{Aa}$ & $11,8 \mathrm{Ba}$ & $10,4 \mathrm{Bb}$ \\
\hline $10-15$ & $1,72 \mathrm{ABa}$ & $1,71 \mathrm{Ba}$ & $0,177 \mathrm{BCa}$ & $0,183 \mathrm{Ca}$ & $0,182 \mathrm{Aa}$ & $0,171 \mathrm{Ba}$ & $0,359 \mathrm{Ba}$ & $0,354 \mathrm{Ba}$ & & & $8,8 \mathrm{Cb}$ & $12,2 \mathrm{Ba}$ \\
\hline $15-20$ & $1,76 \mathrm{Ab}$ & $1,82 \mathrm{Aa}$ & $0,159 \mathrm{Ca}$ & $0,13 \mathrm{Db}$ & $0,178 \mathrm{ABa}$ & $0,181 \mathrm{Aa}$ & $0,337 \mathrm{Ca}$ & $0,314 \mathrm{Cb}$ & $11,1 \mathrm{Ba}$ & $5,1 \mathrm{Bb}$ & $8,5 \mathrm{Ca}$ & $8,6 \mathrm{Ca}$ \\
\hline $\mathrm{CV}(\%)$ & \multicolumn{2}{|c|}{1,9} & \multicolumn{2}{|c|}{5,0} & \multicolumn{2}{|c|}{2,1} & \multicolumn{2}{|c|}{2,5} & \multicolumn{2}{|c|}{18,0} & \multicolumn{2}{|c|}{4,3} \\
\hline
\end{tabular}

1/ Condutividade hidráulica saturada, nas profundidades de $0-10$ e $10-20 \mathrm{~cm}$.

$\mathrm{SD}=$ semeadura direta; e $\mathrm{PC}=$ preparo convencional.

Médias seguidas pela mesma letra maiúscula nas colunas e minúscula nas linhas não diferem pelo teste de Tukey (P > 0,05).

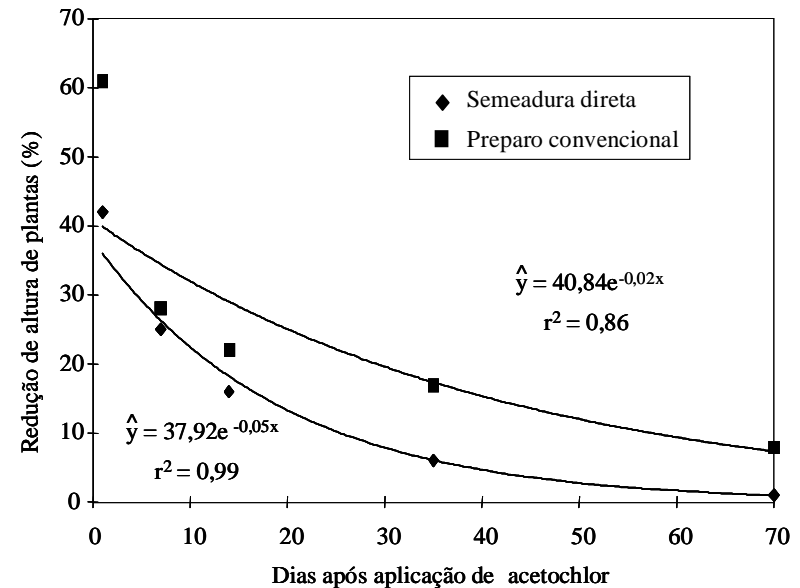

Figura 1 - Redução de altura de plantas do trigo (\%) no tempo, devido à aplicação do herbicida acetochlor em Argissolo Vermelho sob semeadura direta e preparo convencional. UFRGS, Porto Alegre-RS, 1999/2000.

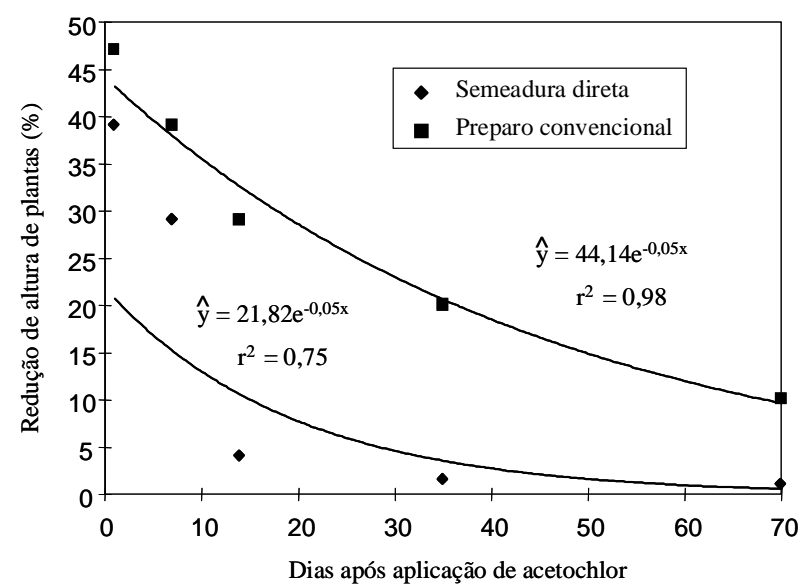

Figura 2 - Redução da matéria seca da parte aérea de trigo (\%) no tempo pelo acetochlor, em solo submetido aos sistemas de semeadura direta e convencional. Porto AlegreRS, 1999/2000. 
A semeadura direta, em relação ao preparo convencional, normalmente altera a umidade, a temperatura, o $\mathrm{pH}$ e o teor superficial de matéria orgânica do solo. Além disso, a manutenção da estabilidade da estrutura, decorrente da ausência de preparo e presença da palha na superfície do solo, pode incrementar a infiltração de água (Thomas \& Phillips, 1979; Dick, 1983; Crawford, 1994) e favorecer a lixiviação de herbicidas. O ambiente edáfico originado normalmente incrementa a diversidade, a atividade e a biomassa microbiana, acentuando a degradação e/ou transformação biológica de herbicidas aplicados nesses solos (Walker et al., 1992; Mueller et al., 1999). Dessa forma, a alteração na condutividade hidráulica saturada, o incremento do teor superficial de matéria orgânica (Tabela 1) e a presença de palha na superfície do solo sem preparo podem favorecer a dissipação de acetochlor neste sistema de manejo, em razão do incremento da lixiviação, adsorção e degradação biológica deste herbicida, no Argissolo Vermelho sob semeadura direta.

A curva de calibração, obtida pela análise de regressão dos valores de porcentagem de redução de altura de plantas em função de doses do herbicida acetochlor, não indicou diferenças de desempenho deste herbicida em solo sob semeadura direta e preparo convencional. Essa curva é composta de três segmentos lineares, em que o efeito mais pronunciado do herbicida foi constatado em doses compreendidas entre 0 e $210 \mathrm{~g} \mathrm{ha}^{-1}$ (Figura 3). Utilizando-se a curva de calibração e a porcentagem de redução de altura de plantas em várias épocas (Figura 1), determinouse a biodisponibilidade do herbicida acetochlor no solo Argissolo Vermelho sob semeadura direta e preparo convencional (Tabela 2). Pela cinética de dissipação de herbicidas no solo, observou-se variação na persistência do herbicida acetochlor entre Argissolo Vermelho sob semeadura direta e preparo convencional, com taxas de dissipação (k) de 0,0668 e 0,0241 dia-1, respectivamente (Tabela 3 ).

A concentração do herbicida acetochlor variou entre os sistemas de manejo, sendo verificada sua presença no solo por um período de 35 e 70 dias para o sistema de semeadura direta e preparo convencional, respectivamente
(Tabela 2). Além disso, a cinética de degradação do herbicida acetochlor no solo determinou meia-vida $\left(\mathrm{t}_{1 / 2}\right)$ de 10 e 29 dias para o Argissolo Vermelho sob semeadura

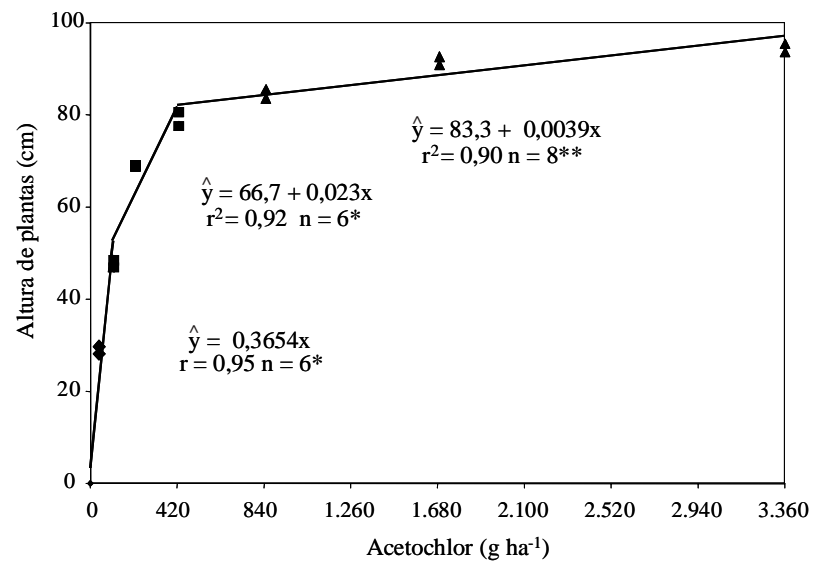

$*$ e $* *$ significativo a $5 \%$ e a $1 \%$ de probabilidade, respectivamente.

Figura 3 - Porcentagem de redução da altura da plantas de trigo em função de doses do herbicida acetochlor. EEA/ UFRGS, Eldorado do Sul-RS, 1999/2000.

Tabela 2 - Biodisponibilidade do herbicida acetochlor em Argissolo Vermelho em função da época de avaliação e preparo do solo. UFRGS, Porto Alegre-RS, 1999/2000

\begin{tabular}{|c|c|c|}
\hline \multirow{2}{*}{$\begin{array}{c}\text { Época de } \\
\text { avaliação }\end{array}$} & \multicolumn{2}{|c|}{ Preparo de solo } \\
\cline { 2 - 3 } & \multicolumn{2}{|c|}{ acetochlor no solo $\left(\mathrm{g} \mathrm{ha}^{-1}\right)$} \\
\cline { 2 - 3 } & $115 \pm 31^{\underline{2} /}$ & $167 \pm 5$ \\
1 DAT $^{1 /}$ & $69 \pm 16$ & $77 \pm 19$ \\
$7 \mathrm{DAT}$ & $44 \pm 5$ & $62 \pm 17$ \\
$14 \mathrm{DAT}$ & $16 \pm 16$ & $47 \pm 4$ \\
$35 \mathrm{DAT}$ & 0,0 & $23 \pm 7$ \\
$70 \mathrm{DAT}$ &
\end{tabular}

1/ DAT $=$ dias após aplicação de acetochlor.

2/ Intervalo de confiança para média a $5 \%$ de probabilidade pelo teste t.

Tabela 3 - Coeficiente de correlação ( $\mathrm{r}$ ), constante de dissipação $(\mathrm{k})$ e meia-vida $\left(\mathrm{t}_{1 / 2}\right)$ do herbicida acetochlor em Argissolo Vermelho com ou sem preparo, na presença ou ausência de palha. UFRGS, Porto Alegre-RS, 1999/2000

\begin{tabular}{|c|c|c|c|}
\hline Preparo do solo & $\begin{array}{c}\text { Coeficientes } \\
\text { de correlação }(\mathrm{r})\end{array}$ & $\begin{array}{c}\mathrm{K} \\
\left(\mathrm{dia}^{-1}\right)\end{array}$ & $\begin{array}{c}\mathrm{t}_{1 / 2} \\
(\mathrm{dia})\end{array}$ \\
\hline Sem preparo & $0,98^{* *}$ & $6,68 \times 10^{-2}$ & 10 \\
Com preparo & $0,92 *$ & $2,41 \times 10^{-2}$ & 29 \\
\hline
\end{tabular}

* Significativo a $5 \%$ de probabilidade.

** Significativo a $1 \%$ de probabilidade. 
direta e preparo convencional, respectivamente (Tabela 3 ).

Os valores de meia-vida obtidos neste trabalho estão dentro dos limites normalmente observados para outros herbicidas integrantes do grupo cloroacetamidas. Variações de dissipação de herbicidas cloroacetamidas normalmente ocorrem entre solos sob semeadura direta e preparo convencional (Zimdahl \& Clark, 1982). A transformação de alachlor, por exemplo, pode ser rápida no solo, com $t_{1 / 2}$ entre 2 e 60 dias, dependendo das características edafoclimáticas (Beestman \& Deming, 1974; Pothuluri et al., 1990; Walker et al., 1992). Por sua vez, Mueller et al. (1999) observaram $t_{1 / 2}$ de herbicida acetochlor no solo de apenas seis dias, sugerindo como as responsáveis por esse tal efeito as altas temperatura e umidade, aliadas à fraca adsorção devido ao baixo teor de matéria orgânica e argila do solo.

A redução da persistência do herbicida acetochlor no solo pode resultar da interação de processos de natureza física, química e biológica, porque estes sofrem influência marcante do manejo do solos. Assim, a menor persistência do herbicida acetochlor no solo sob semeadura direta provavelmente decorra de alterações nos niveis de matéria orgânica (Tabela 1), que, aliadas a presença da palha na superfície do solo e aos seus possiveis efeitos sobre a umidade e temperatura do solo, podem ter favorecido a biomassa e atividade microbiana e, em função disso, a transformação biológica deste herbicida, neste sistema de manejo do solo.

Com base nos resultados observados, conclui-se que o herbicida acetochlor foi menos persistente no solo Argissolo Vermelho sob semeadura direta, comparado ao preparo convencional, com meia-vida de 10 e 29 dias, respectivamente. Propõe-se que as alterações nas propriedades físicas, químicas e biológicas promovidas pelo manejo do solo através da semeadura direta sejam as responsáveis por isso.

\section{LITERATURA CITADA}

BESTMAN, G. B.; DEMING, J. M. Dissipation of acetanilide herbicides from soils. Agron. J., v. 66, n. 1, p. 308-311, 1974.

Planta Daninha, Viçosa-MG, v.20, n.1, p.133-139, 2002
BLEWINS, R. L. et al. Influence of conservation tillage on soil properties. J. Soil Water Conserv., v. 38, n. 1, p. 301305, 1983.

CRAWFORD, J. W. The relationship between structure and the hydraulic conductivity of soil. Europ. J. Soil Sci., v. 45, n. 2, p. 493-502, 1994.

DICK, W.A. Organic carbon, nitrogen, and phosphorus concentrations and $\mathrm{pH}$ in soil profiles as affected by tillage intensity. Soil Sci. Soc. Am. J., v. 47, n. 1, p. 102-107, 1983.

DURIGAN, J. C. et al. Períodos de matocompetição na cultura da soja (Glycine max L.) Merrill), cultivares Santa Rosa e IAC-2. I. - Efeitos sobre os parâmetros de produção. Planta Daninha, v. 2, n. 1, p. 86-100, 1983.

EMPRESA BRASILEIRA DE PESQUISA AGROPECUÁRIA - EMBRAPA. Centro Nacional de Pesquisa de Solos. Rio de Janeiro-SNLCS. Manual de métodos de análise do solo. Rio de Janeiro: 1979. 1010 p.

EMPRESA BRASILEIRA DE PESQUISA AGROPECUÁRIA - EMBRAPA. Serviço Nacional de Pesquisa de Solos. Sistema Brasileiro de Classificação de Solo. Rio de Janeiro: 1999, 412 p.

FLECK, N. G. et al. Interferência de plantas daninhas na cultura de girassol. Competição no tempo. Pesq. Agropec. Bras., v. 24, n. 9, p. 1139-1147, 1989.

GAZZIERO, D. L. P. et al. Persistência dos herbicidas imazaquin e imazethapyr no solo e os efeitos sobre plantas de milho e pepino. Planta Daninha, v. 15, n. 2, p. 162-169, 1997.

ISENSEE, A. R.; NASH, R. G.; HELLING, C. S. Effects of conventional vs. no-tillage on pesticide leaching to shallow groundwater. J. Environ. Quality, v. 19, p. 434-440, 1990.

MUELLER, T. C.; SHAW, D. R.; WITT, W. W. Relative dissipation of acetochlor, alachlor, metolachlor and SAN 582 from three surface soils. Weed Technol., v. 13, n. 1, p. 341-346, 1999.

PAUL, E. A.; CLARK, F. E. Soil microbiology and biochemistry. 2.ed. San Diego: Academic Press, 1989. $340 \mathrm{p}$.

POTHULURI, J. V. et al. Aerobic and anaerobic degradation in samples from a surface-to-groundwater profile. J. Environ. Quality, v. 19, n. 2, p. 525-530, 1990.

REDDY, K. N.; ZABLOTOWICZ, R. M.; LOCKE, M. A. Chlorimuron adsorption, desorption and degradation in soils from conventional tillage and no-tillage systems. J. Environ. Quality, v. 24, p. 760-767, 1995. 
RHOTON, F. E. et al. Chemical and physical characteristics of four soil types under conventional and no-tillage systems. Soil Tillage Res., v. 28, n. 1, p. 51-61, 1993.

SHAW, D. R.; MURPHY, G. P. Field pesistence of bioavailable flumetsulam. Weed Sci., v. 45, n. 2, p. 568-572, 1997.

SHIPITALO, M. J.; DICK, W. A.; EDWARDS, W. M. Conservation tillage and macropore factors that affect water movement and the fate of chemicals. Soil Tillage Res., v. 53, n. 3-4, p. 167-183, 2000.

STEARMAN, G. K.; WELLS, J. M. Leaching and runoff of simazine, 2,4-D, and bromide from nursery plots. J. Soil Water Conser., v. 52, n. 1, p. 137-144, 1997.

TEDESCO, M. J. et al. Análises de solo, plantas e outros materiais. Porto Alegre: Universidade Federal do Rio Grande do Sul, 1995. 174 p. (Boletim Técnico de Solos, 5).
THOMAS, G. W.; PHILLIPS, R. E. Consequences of water movement in macroporos. J. Environ. Quality, v. 8, n. 2, p.149-152, 1979.

ZIMDAHL, R. L.; CLARK, S.K. Degradation of three acetamide herbicides in soil. Weed Sci., v. 30, n. 2, p. 545548, 1982.

WALKER, A.; MOON, Y.; WELCH., S. J. Influence of temperature, soil moisture and soil characteristics on the persistence of alachlor. Pest. Sci., v. 35, n. 1, p. 109-116, 1992.

WEED, D. A. J. et al. Dissipation and distribution of herbicides in the soil profile. J. Environ. Quality, v. 24, n. 1, p. 68-79, 1995.

WILLIAM, T.W. et al. Norflurazon adsorption and dissipation in three southern soils. Weed Sci., v. 45, n. 1, p. 301-306, 1997.

WORKMAN, S. R. et al. Atrazine and alachlor dissipation rates from field experiments. Trans. Am. Soc. Agron.

Eng., v. 38, n. 5, p. 1421-1425, 1995. 